CrossMark

\title{
Personalised medicine in sleep respiratory disorders: focus on obstructive sleep apnoea diagnosis and treatment
}

\author{
Maria R. Bonsignore ${ }^{1,2}$, Monique C. Suarez Giron ${ }^{3}$, Oreste Marrone², \\ Alessandra Castrogiovanni ${ }^{1}$ and Josep M. Montserrat ${ }^{3,4}$
}

Number 2 in the Series "Personalised medicine in respiratory diseases" Edited by Renaud Louis and Nicolas Roche

Affiliations: ${ }^{1}$ Biomedical Dept of Internal and Specialistic Medicine (DiBiMIS), University of Palermo, Palermo, Italy. ${ }^{2}$ Institute of Biomedicine and Molecular Immunology (IBIM), National Research Council (CNR), Palermo, Italy. ${ }^{3}$ Sleep Unit, Hospital Clinic, Barcelona, Spain. ${ }^{4}$ Centro de Investigación Biomédica en Red de Enfermedades Respiratorias (CIBERES), Madrid, Spain.

Correspondence: Maria R. Bonsignore, DiBiMIS, University of Palermo, Via Trabucco 180, 90146 Palermo, Italy. E-mail: marisađibim.cnr.it

@ERSpublications

Physiological and clinical phenotyping of OSA patients will improve the management of the disease http://ow.ly/qSxq30f9Hp8

Cite this article as: Bonsignore MR, Suarez Giron MC, Marrone O, et al. Personalised medicine in sleep respiratory disorders: focus on obstructive sleep apnoea diagnosis and treatment. Eur Respir Rev 2017; 26: 170069 [https://doi.org/10.1183/16000617.0069-2017].

ABSTRACT In all fields of medicine, major efforts are currently dedicated to improve the clinical, physiological and therapeutic understanding of disease, and obstructive sleep apnoea (OSA) is no exception. The personalised medicine approach is relevant for OSA, given its complex pathophysiology and variable clinical presentation, the interactions with comorbid conditions and its possible contribution to poor outcomes. Treatment with continuous positive airway pressure (CPAP) is effective, but CPAP is poorly tolerated or not accepted in a considerable proportion of OSA patients. This review summarises the available studies on the physiological phenotypes of upper airway response to obstruction during sleep, and the clinical presentations of OSA (phenotypes and clusters) with a special focus on our changing attitudes towards approaches to treatment. Such major efforts are likely to change and expand treatment options for OSA beyond the most common current choices (i.e. CPAP, mandibular advancement devices, positional treatment, lifestyle changes or upper airway surgery). More importantly, treatment for OSA may become more effective, being tailored to each patient's need.

Previous articles in this series: No. 1: Chung KF. Personalised medicine in asthma: time for action. Eur Respir Rev 2017; 26: 170064.

Received: June 152017 | Accepted: Aug 142017

Conflict of interest: None declared.

Provenance: Commissioned article, peer reviewed.

Copyright OERS 2017. ERR articles are open access and distributed under the terms of the Creative Commons Attribution Non-Commercial Licence 4.0. 


\section{Introduction}

The concept of personalised medicine has gained popularity among respiratory clinicians in recent years. The identification of phenotypes of asthma $[1,2]$ or chronic obstructive pulmonary disease (COPD) [3-5] has boosted a major change in the way we diagnose and treat these diseases and has widened our perspective for new treatments. In patients with lung cancer, innovative treatments have been developed towards specific molecular targets, with increased efficacy and improved outcomes compared to traditional chemotherapy $[6,7]$.

Obstructive sleep apnoea (OSA) is a highly prevalent disease, and its pathophysiology continues to be a major challenge for both basic researchers and clinicians. Some years ago, phenotyping of OSA patients was mostly perceived as an essential step to dissect the genetic background of the disease. More recently, availability of "big data" for OSA $[8,9]$ and sophisticated analysis techniques have considerably expanded the possibility of gaining insight into the variability of physiological traits, clinical presentations and biomarkers, with the potential application of results in clinical practice. Over the years, we have learned about the potential effects of OSA in increased cardiovascular morbidity and mortality [10], cognitive dysfunction [11] and traffic accidents [12], and its association with major diseases such as hypertension [13], diabetes [14] and cancer [15] and the relevant effects of chronic intermittent hypoxia in visceral fat [16, 17]. However, if personalised medicine has to be implemented in basic and clinical research on OSA, we are still in a very initial phase of such development, since some pieces of the puzzle have been identified, but their application in clinical practice remains limited or absent.

As highlighted in a recent review [18], there are many levels that have to be considered in dissecting the steps leading to the different phenotypes of OSA before a personalised clinical and therapeutic approach can be successfully developed (figure 1). Moreover, differences are evident between OSA in children, adults and the elderly, and little is known about the evolution of sleep disordered breathing over the lifespan. Recent studies suggest that childhood obesity increases the risk of developing OSA in adulthood [19],

Data levels

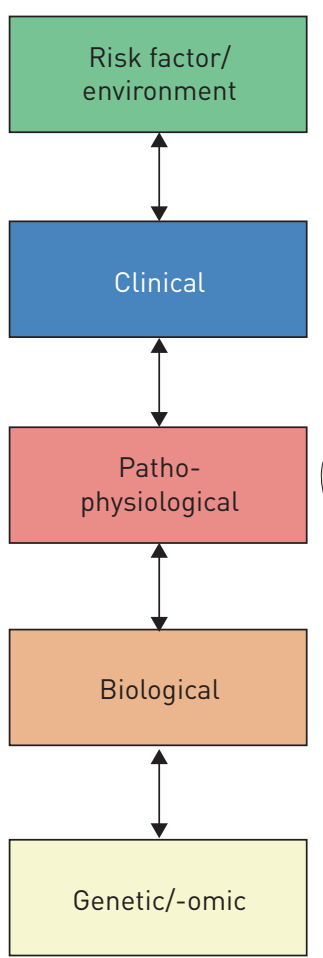

Component examples

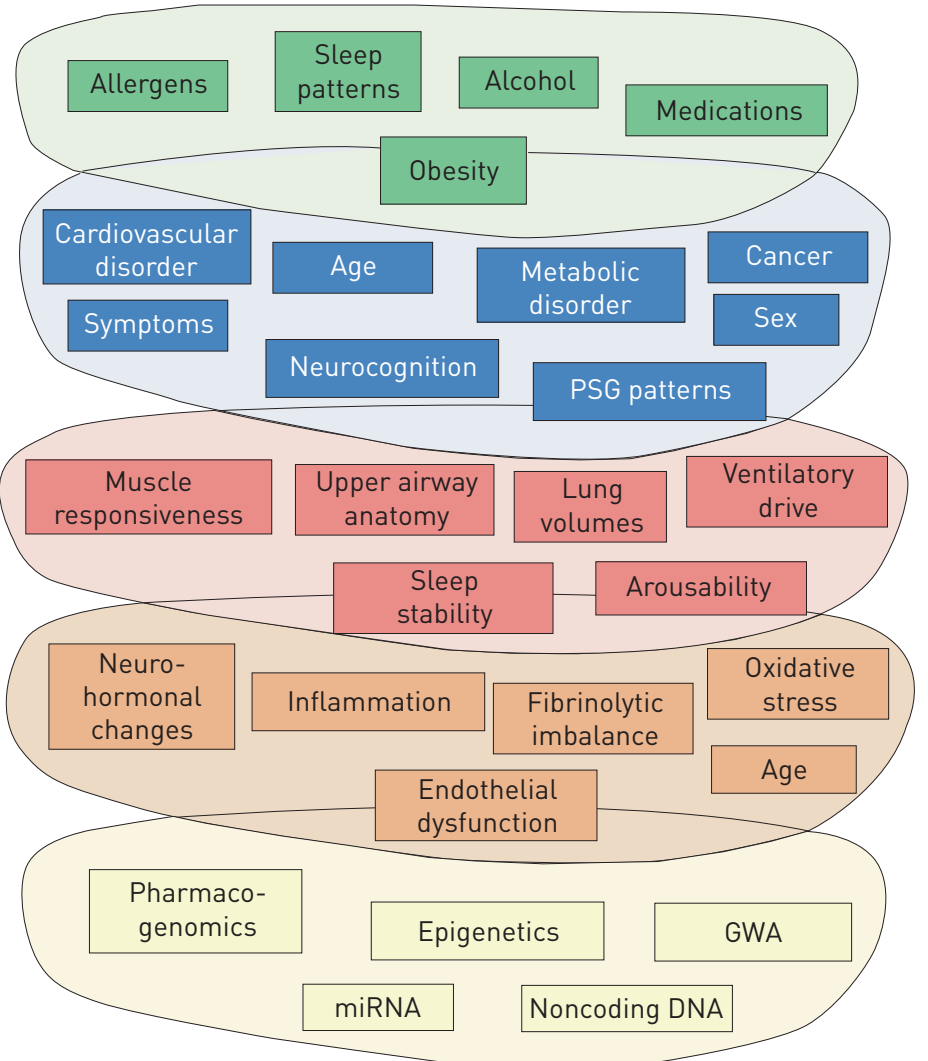

Potential clinical relevance (selected examples)

Lifestyle

- Modifiable factors (weight loss)

Clinical phenotypes

- Integrated care

- Risk stratification (EDS, elderly)

- Comprehensive guidelines

\section{Intermediate phenotypes}

- Therapeutic targets

(oxygen, sedatives)

- Diagnostic (PALM)

- Therapy response (CCC)

Biomarkers

- Diagnostic (IL-6, IL-10)

- Therapeutic targets

- Sequelae predisposition

Genetic risk assessment

- OSA risk

- Sequelae predisposition

- Response to therapy (miRNAs and resistant HTN)

FIGURE 1 The complexity of obstructive sleep apnoea (OSA) for consideration in a personalised medicine approach. PSG: polysomnography; GWA: genome-wide association; EDS: excessive daytime sleepiness; PALM: Pcrit (passive critical closing pressure), arousal threshold, loop gain and muscle responsiveness; CCC: complete concentric palatal collapse; IL: interleukin; HTN: systemic hypertension. Reproduced and modified from [18] with permission. 
but the role of genetic traits is poorly understood, since studies on the genetics of OSA are limited in number and include small samples of patients $[20,21]$. Heritable differences in craniofacial structures have been shown between OSA patients and controls [22, 23], but sophisticated analyses may be necessary to identify heritable traits in a complex disease such as OSA [21]. Finally, OSA shows major sex- [24] and age-related [25] differences in clinical and polysomnographic presentation, further complicating the overall clinical picture.

This review focuses on recent work on the physiological and clinical aspects of OSA, including predictors of poor compliance to CPAP treatment and associated comorbidities, with regard to data suggesting individualised approaches to treatment. Readers are referred to other recent reviews for updated information on personalised medicine in OSA, including biomarkers and "omic" approaches [26-31].

\section{Physiological traits}

Current prevalence of sleep disordered breathing (SDB) is $10-17 \%$ in males and $3-9 \%$ in females [30]. The most common form of SDB is obstructive sleep apnoea (OSA), characterised by frequent breathing pauses due to sleep-related changes in muscle tone; the increased airway resistance leads to partial (hypopnoea) or complete (apnoea) upper airway collapse. The acute effects of these events include repeated drops in oxyhaemoglobin saturation, cardiovascular perturbations and cortical arousals, which fragment sleep [31].

It is clear that the pathophysiology of OSA is multifactorial, and caused not only by an impaired upper airway anatomy (i.e. anatomically narrow/collapsible airway), but also by several non-anatomical factors [32, 33], known as physiological traits, that combined have been shown to cause OSA [34, 35]. These include 1) poor upper airway anatomy which predisposes the airway to collapse; 2) poor ability of the upper airway muscles to respond to a respiratory challenge and stiffen or dilate the airway; 3 ) a low respiratory arousal threshold that causes an individual to arouse from sleep for very small increases in respiratory drive; and 4) a hypersensitive ventilatory control system, often referred to as a system with a high loop gain [35-37].

The contribution of each of these traits varies between patients and within different severities of disease [32], resulting in substantial heterogeneity between OSA patients, and possibly contributing to the results of continuous positive airway pressure (CPAP) treatment. Since adherence to CPAP is highly variable, an alternative approach for nonadherent patients would be to manipulate one or more of the underlying traits that contribute to OSA pathogenesis [38]. If a reliable and accurate pathophysiological pattern for each patient with OSA/hypopnoea syndrome could be identified, a customised therapy would be feasible in the future [39]. Here, we discuss the main characteristics of these traits as they relate to OSA pathophysiology.

\section{Anatomical traits in OSA}

The upper airway, from the posterior end of the nasal septum to the epiglottis, has relatively little bony or rigid support. The two primary forces tending to collapse the airway are the intraluminal negative pressure generated by the diaphragm during inspiration and the extraluminal tissue pressure from tissue and bony structures surrounding the airway [37, 40]. Different approaches have been developed to assess the functional and anatomical impairment of the upper airway in OSA, such as computed tomography (CT), magnetic resonance imaging (MRI), cephalometry, nasopharyngoscopy and drug-induced sleep endoscopy (DISE). The latter two provide information about the airway during static, awake or pharmacologically induced sleep states [41].

Upper airway anatomy

Obesity is a major cause of a narrow pharyngeal airway. Obesity can crowd the upper airway via deposition of adipose tissue in regions surrounding the airway. Recent evidence obtained using MRI suggests that many people with OSA have increased fat within their tongues compared to equally obese people without OSA [42-44]. Additionally, reduced tongue stiffness may contribute to increase upper airway collapsibility [45]. Nevertheless, some individuals gain weight without major upper airway compromise, and overweight/obese individuals without apnoea show a moderately compromised upper airway structure associated with highly responsive upper airway dilator muscles. Elucidating the mechanisms underlying other, non-anatomical traits can shed light on factors protecting against OSA [46].

The use of quantitative imaging techniques has shown differences in both the craniofacial structures and the soft tissues of the upper airway in OSA patients. Size and position of cranial bones (reduced length of mandibular body, low hyoid bone and retropositioning of the jaw) results in a reduction in pharyngeal airspace [40]. Increased upper airway length is associated with greater susceptibility to airway narrowing/ collapse; the pharyngeal length is defined as the distance from the posterior nasal spine to the base of the epiglottis, which is attached to the hyoid. Consistent with this concept, an anatomically long upper airway, 
particularly in males, and an inferiorly displaced hyoid bone are anatomical features associated with OSA, easily detected in CT scans of the upper airway which provide three-dimensional reconstructions of the tongue and upper airway $[42,44]$.

Other methods have been used to evaluate the upper airway and investigate the severity and location of obstruction. Kiм et al. [47] used fibre-optic nasopharyngoscopy with Muller manoeuvres to identify the anatomical level and degree of pharyngeal narrowing in OSA patients, revealing a correlation with the apnoea/hypopnoea index (AHI). Using sleep endoscopy in suspected OSA patients, BACHAR et al. [48] found that the velopharynx was the most common site of obstruction (89\% of patients), and most of the patients (72\%) had multiple sites of obstruction. HuON et al. [41] observed more multilevel and lateral pharyngeal wall collapse in patients with severe OSA compared to body mass index (BMI)-matched mild OSA patients, by using sleep MRI. These data may explain the poor predictive value of single measurements of airway anatomy and the relatively high failure rate of uvulopalatopharyngoplasty (UPPP) surgery $[49,50]$.

\section{Upper airway collapsibility: intraluminal negative pressure}

The mechanics of the upper airway in sleep apnoea/hypopnoea syndrome has been interpreted by means of a collapsible resistor model characterised by its critical pressure $\left(P_{\text {crit }}\right)$ and its upstream resistance. $P$ crit is the gold standard for measuring upper airway collapsibility and is defined as the minimal intraluminal airway pressure necessary to keep the collapsible segment open [51]. Therefore, if nasal CPAP is lower than $P_{\text {crit, }}$ the upper airway is collapsed during inspiration and the patient experiences apnoeas [52].

To measure $P$ crit, the participant wears a CPAP mask attached to a modified CPAP device delivering both positive and negative pressures. In people with OSA, Pcrit is their therapeutic CPAP level, while in people without OSA it is $\sim 4-5 \mathrm{cmH}_{2} \mathrm{O}$. CPAP is then transiently lowered (for up to five breaths), sometimes to negative suction pressures, to induce variable degrees of airflow limitation, ideally (if arousals do not occur) until upper airway collapse. The technique relies on the assumption that CPAP reduces dilator muscle activity, which remains low following brief reductions in CPAP [51]. Pcrit is calculated by performing linear regression between the peak inspiratory flows for breaths 3-5 following the reduction in CPAP; breaths 1-2 following the transient reduction in CPAP are not included in the calculation, because lung volume changes that occur with the rapid reduction in CPAP take one or two breaths to stabilise [42, 53]. Increases in lung volumes probably exert caudal traction on the upper airway, preventing its collapse. This observation may help explain the link between obesity and OSA and other clinical observations, such as the improvement in OSA when sleeping upright [49].

The pharyngeal $P$ crit is associated with obesity and hyoid position. Tongue dimensions, pharyngeal length and the distance from the mandibular plane to the hyoid are all associated with obesity variables [44]. As for the effect of body position, Pcrit increases (i.e. airway is more collapsible) in the supine sleeping position, whereas lateral positioning significantly improves passive airway anatomy/collapsibility [33]. As a consequence, a lower CPAP pressure is needed in the lateral position than in the supine position [54].

Instead of measuring $P_{\text {crit, }}$ negative expiratory pressure (NEP) can be applied noninvasively during spontaneous expiration during wakefulness to evaluate expiratory flow limitation. NEP is a simple measurement, first described to evaluate intrathoracic expiratory flow limitation in patients with COPD. It has been used to assess upper airway collapsibility in patients with suspected OSA [55]. Application of NEP while awake in the supine position is a simple and promising method that correlates with the anatomical component of upper airway collapsibility [56].

\section{Non-anatomical traits}

Upper airway dilator muscles

For upper airway dilator muscles to hold open the narrow pharyngeal airway of OSA patients and protect against collapse, the muscles must respond to collapsing forces by increasing their activity, to effectively reopen the upper airway [42]. Upper airway dilator muscles comprise phasic and tonic muscles. Activity of the phasic muscles increases during inspiration, resulting in stabilisation and expansion of the upper airway to counterbalance the effect of negative upper airway pressure; their activity is reduced but not completely abolished during expiration when pressure in the upper airway becomes positive. In contrast, the activity of tonic muscles remains constant in the respiratory cycle [40].

Upper airway dilator muscles: neural drive, responsiveness and effectiveness.

Much of the work on the influence of sleep on pharyngeal muscle control and patency in humans has focused on the genioglossus muscle (GGM) and, to a lesser extent, on the tensor palatine muscle. The GGM has an electromyogram (EMG) activity that is typically inspiratory phasic (greater activity on 
inspiration), and functions as a dilator of the pharyngeal airway. Meanwhile, tensor palatini activity is typically more constant (tonic) throughout the respiratory cycle [57, 58].

The neural drive to the upper airway dilator muscles is integrated at the level of brainstem motor nuclei where multiple neural inputs combine to produce a unitary output to the muscles. For example, the hypoglossal nucleus, which controls the GGM, receives inputs from premotor pacemaker neurons of the respiratory pattern generator, upper airway negative-pressure receptors, chemoreceptors and stretch receptors. During wakefulness this activity is augmented; at sleep onset the activity of the upper airway dilator muscles is diminished or lost and may underlie the airway collapse $[41,58]$.

OSA patients have greater EMG activity of the GGM and tensor palatini muscle during wakefulness compared to healthy controls. In contrast, during sleep, GGM activity decreases more in OSA patients than controls. The tonic activity of the tensor veli palatini muscle gradually decreases during sleep, and during slow-wave non-rapid eye movement (REM) sleep its activity is only $30 \%$ that when the subject is awake [40]. Some patients with OSA spontaneously overcome their tendency for airway collapse and have stable breathing during part of their sleep, increasing their GGM activity. During respiratory events in REM sleep, the tonic activity of the GGM is reduced even below the level during respiratory events in non-REM sleep phase 2 . However, some subjects, despite activating their GGM, are not able to stabilise their breathing during sleep [59].

Upper airway muscle responsiveness depends on capability for increased activity when challenged with respiratory stimuli (such as hypercapnia and pharyngeal pressure changes) during sleep [42]. Although the tensor palatini can increase its activity in response to respiratory stimuli during sleep, it does not seem to be as sensitive as the GGM. As a result, tensor palatini activity is commonly quite low during sleep, despite elevations in both upper airway resistance and arterial carbon dioxide tension. The drive to several pharyngeal muscles appears to be reduced during sleep, as does their responsiveness to both chemical and mechanical stimuli [57]. Other studies have pointed to changes in respiratory timing and GGM activity during partial upper airway collapse; however, despite such activation, obese patients with OSA could restore airflow and ventilation less often than nonsnorers [60].

Muscle effectiveness is defined as the ability to translate the neural drive received by the upper airway muscles into airway dilation. OSA patients who have poor muscle responsiveness have poor muscle effectiveness too [42]. Muscle effectiveness can be assessed in different ways; some methods use gradual reductions in CPAP and compare responses in the passive versus active state where upper airway dilator muscles have low and high activity, respectively. Using this technique, the improvement in upper airway function with increased muscle activity was greater in healthy controls than in OSA patients [32, 46]. The mechanisms are not yet clear, but poor coordination of the neural drive to upper airway muscles during sleep, mechanically inefficient muscle (due to excess fat or muscle hypertrophy) [43] or muscle fibre type changes [45] could all be contributing factors [42, 61, 62].

BROwn et al. [45] quantified the physical movement of the tongue across the respiratory cycle in patients with OSA and controls during wakefulness. In healthy controls the posterior portion of the tongue moved anteriorly in an en bloc fashion during tidal inspiration. In contrast, mild and moderate OSA patients had nonuniform tongue movement, and the tongue moved backwards into the airway in moderate OSA. While no measurements of upper airway dilator muscle activity were made in these patients, this work highlighted that there may be marked variability in effectiveness of muscle contraction (during wakefulness) and differences according to OSA severity.

Ventilatory control and loop gain

Loop gain is an engineering term that describes the stability of a system controlled by negative feedback loops [63]. In the context of OSA, in a closed loop system such as the breathing system, a perturbation in the controlled loop component (the respiratory apparatus or plant) induces changes in the feedback (blood gas tensions) received by the controller (respiratory centres), and in turn produces a compensatory response in the plant [64]. However, the initial response may result in overcorrection of arterial gas changes ("overshoot"). The ventilatory apparatus is then inhibited through the changes in arterial blood gas tensions that resulted in the initial response, and a hypopnoea ensues. If this second hypopnoea is less severe than the first, the disturbance in gas tensions will also be less severe, eliciting a lower response, ultimately resulting in stabilisation of the system. Conversely, if the overshoot results in large changes in arterial gas tensions, the cycle can continue indefinitely [64].

Mathematically, loop gain is defined as the ratio of the initial corrective response (e.g. hyperpnoea) to the initial disturbance (e.g. apnoea). If the corrective response is greater in magnitude than the disturbance (loop gain $>1$ ), then small perturbations have the potential to grow into self-sustaining oscillations and result in perpetual cycling. Conversely, loop gain $<1$ produces decaying oscillations, the magnitude and 
duration of which depend on the strength of the perturbation and are consistent with stable breathing [63]. Unstable ventilatory control is characterised by high loop gain, and probably contributes to cyclical airway obstruction by promoting airway collapse during periods of low ventilatory drive. OSA patients exhibit abnormal control of chemoreflexes, which contributes to increased loop gain.

Loop gain of the respiratory system can be measured during sleep in humans using a proportional assist ventilator (PAV) [64]. Using PAV, over one-third of OSA patients presented high loop gain, defined as an increase of $>5 \mathrm{~L} \cdot \mathrm{min}^{-1}$ in minute ventilation in response to a $1-\mathrm{L} \cdot \mathrm{min}^{-1}$ reduction in minute ventilation induced via a reduction in CPAP for $3 \mathrm{~min}$ under steady-state conditions. Similar to the impaired pharyngeal muscle phenotype, high loop gain is likely to be a particularly important determinant of OSA pathogenesis in people with mild to moderate impairment in upper airway anatomy [65]. These abnormalities have been shown to improve after CPAP treatment, suggesting induced rather than inherent trait abnormalities [66-69].

\section{Arousal threshold}

Obstructive respiratory events during sleep are often associated with brief awakening during sleep (cortical arousal), thereby disrupting sleep continuity. A marked activation of upper airway dilator muscles occurs during arousal [70]. Cortical arousals can be induced by a variety of stimuli and the sensory inputs responsible for respiratory-induced cortical arousals have been studied extensively [71]. In 1990, a landmark study found that increasing inspiratory efforts may be the stimulus to arousal from sleep [72]. Arousal occurs at a similar level of inspiratory effort irrespective of the cause of respiratory stimulation, i.e. hypercapnia, hypoxia or addition of a resistive load [72].

The notion that cortical arousal is required for the airway to open was rapidly accepted and arousal was assigned a "life-saving" role. However, subsequent work [73] showed that cortical arousals are not required to restore airflow at the end of a respiratory event. In fact, cortical arousals are not responsible for airway opening in $\sim 60 \%$ of events: $20 \%$ of events were associated with an arousal only after airway reopening, and $40 \%$ of events were not associated with any arousal [33, 71]. AMATOuRY et al. [74] recently reported that higher arousal intensities result in approximately two-fold greater upper airway muscle activation, but also in $\sim 40 \%$ greater increases in airflow and minute ventilation. Consistent with arousal intensity being a
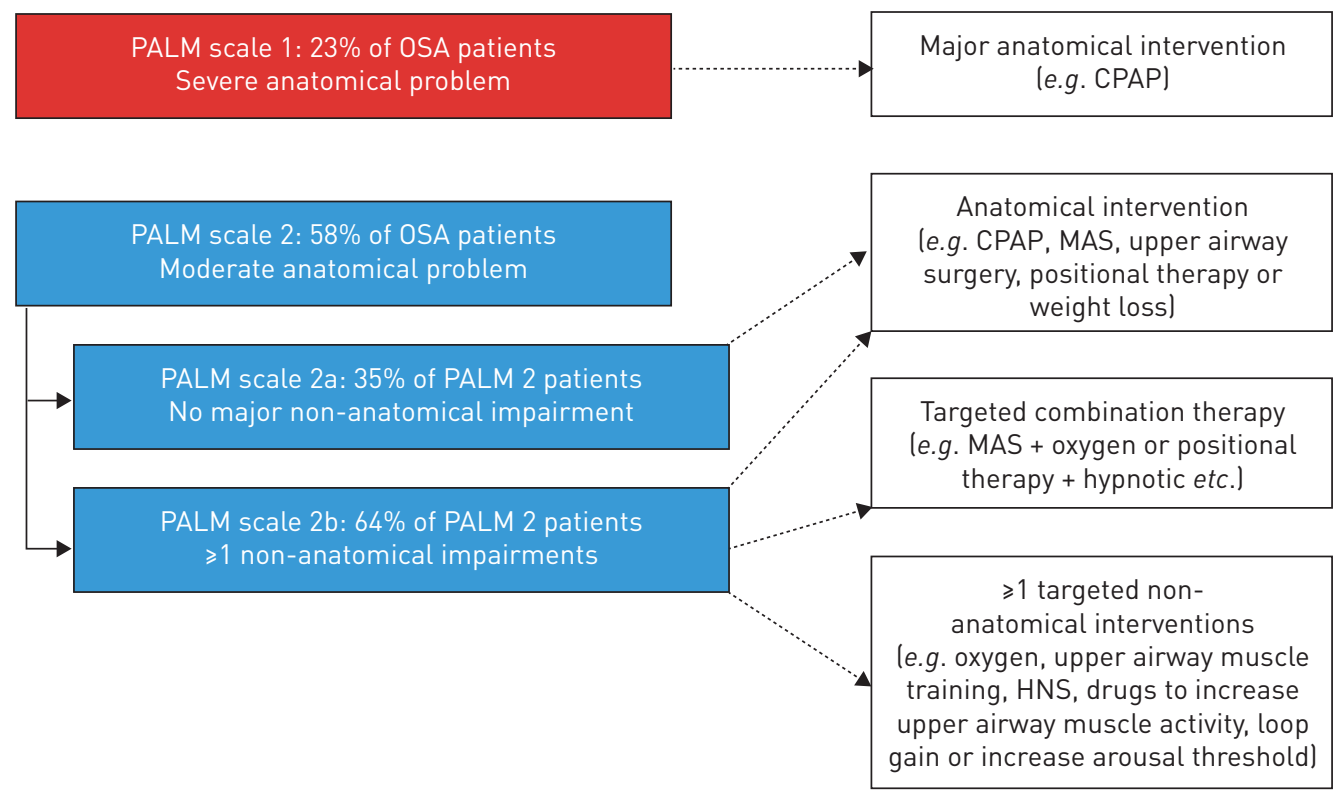

PALM scale $3: 19 \%$ of OSA patients Minor anatomical problem

High probability that $\geqslant 1$ targeted non-anatomical interventions would be efficacious

FIGURE 2 The PALM ( $P_{\text {crit }}$ (passive critical closing pressure), arousal threshold, loop gain and muscle responsiveness) scale approach to personalise obstructive sleep apnoea (OSA) treatment. Therapeutic interventions can be chosen according to the physiological phenotype of each patient. CPAP: continuous positive airway pressure; MAS: mandibular advancement splint; HNS: hypoglossal nerve stimulation. Reproduced and modified from [42] with permission. 
distinct trait and a contributor to OSA pathogenesis, these findings indicate that average arousal intensity is independent of the preceding respiratory stimulus; the physiological responses to arousal vary according to arousal intensity.

In summary, arousals are incidental events that occur when the thresholds for arousal and arousal-independent opening are close to each other, as they appear to be in patients with OSA. Arousals prevent deeper and more stable sleep, promote an unnecessarily high flow response at upper airway opening and help perpetuate respiratory control instability.

\section{The physiological phenotypes of OSA: the PALM scale}

A variable combination of anatomical and functional features of the upper airway occurs in OSA patients, and a better definition of the physiology of upper airway response to obstruction could allow alternative therapeutic approaches beyond CPAP. The PALM scale ( $P$ crit, arousal threshold, loop gain and muscle responsiveness) has been developed to better stratify OSA patients according to upper airway physiology and select appropriate interventions, as summarised in figure 2. In short, if a moderate-to-severe anatomical problem is present (PALM 1 and 2a), there is indication for CPAP treatment or other interventions that modify the upper airway (surgery, mandibular advancement device, positional therapy or lifestyle interventions). As the role of non-anatomical factors becomes more important than upper airway anatomy, one or more interventions for each physiological impairment can be chosen in order to target treatment to improve upper airway muscle function, i.e. upper airway muscle stimulation $[75,76]$, drugs [77], reduction of loop gain using acetazolamide [78] or increase of the arousal threshold using hypnotics [79-83]. While interested readers are referred to extensive reviews on this topic [42, 84, 85], some critical points need to be highlighted. First, the measurement of the PALM variables is still complicated in the clinical setting, as it requires full polysomnography and subsequent processing of a large amount of data. Clearly, this is hard to apply in the clinical context of large numbers of patients referred for OSA diagnosis and treatment. Second, while the physiology of respiratory events in non-REM sleep has been intensively studied, much less is known about REM sleep, a sleep phase characterised by more prolonged and severe events. Third, available interventional studies tailored to physiological traits are still small-scale, short-term, proof-of-concept studies. Since the theoretical and experimental background is quite solid and the first studies appear promising, ongoing research is likely to indicate clinically applicable treatments for specific OSA phenotypes, changing the current scenario of treatment for OSA.

\section{Clinical phenotypes of OSA}

The search for different clinical presentations of OSA has produced interesting results. Initially, OSA phenotypes were described based on the clinical characteristics of the disease, by combining anthropometrics, sleep data and comorbidities in patterns corresponding to the most common clinical presentations of OSA. More recently, cluster analysis has been applied to large series of data. In contrast to hypothesis-driven studies, cluster analysis is a sophisticated statistical methodology that combines several variables to identify groups of patients with distinct phenotypes, i.e. clusters.

In recent years, phenotype and cluster analyses have been applied to the clinical features of OSA patients, as summarised in table 1 . Variability in results can be expected, since the studies differed in the variables entered in the analyses. In addition, the studies are heterogeneous in the number of patients included, and only three studies were multicentric $[89,90,93]$. Finally, the complexity of OSA can affect the results. A good example is provided by an interesting study on the polysomnographic features of mild-to-moderate OSA [86], which identified seven clinical phenotypes and six clusters. Some clinical phenotypes corresponded to two clusters each, while for other clinical phenotypes no cluster could be identified [86]. Positional OSA and sleep stage-dependent OSA appear to be variably combined in clinical practice, and other variables, such as the clinical characteristics of the patients, were not included in the analysis, possibly explaining the lack of precision in the identification of clusters.

While there may be inherent limitations in single-centre studies, as discussed above, they were important in identifying clinically relevant phenotypes to be tested in subsequent large studies. The first cluster analysis on OSA clinical phenotypes was published by the Icelandic Sleep Apnea Cohort (ISAC) research group, in $>800$ consecutive patients with newly diagnosed moderate-to-severe OSA [87]. Three main clusters were identified, corresponding to the "disturbed sleep", the "minimally symptomatic" and the "excessive daytime sleepiness (EDS)" phenotypes. This study highlighted that these groups showed similar sleep variables, such as AHI or degree of obesity. EDS was often absent in OSA patients, and patients reported symptoms of insomnia rather than sleepiness. Moreover, the association of OSA and comorbidities was more frequent in the minimally symptomatic group, which included asymptomatic OSA patients with cardiovascular and respiratory comorbidities. The European Sleep Apnea Database (ESADA) study analysed similar OSA phenotypes, i.e. a combination of diurnal and nocturnal symptoms, in a 
TABLE 1 Studies on clinical phenotypes/cluster analysis in patients with obstructive sleep apnoea (OSA)

\begin{tabular}{|c|c|c|c|c|c|c|c|c|c|}
\hline $\begin{array}{c}\text { First author } \\
\text { [ref.].] }\end{array}$ & Methodology & Group 1 & Group 2 & Group 3 & Group 4 & Group 5 & Group 6 & Group 7 & Group 8 \\
\hline Joosten [86] & $\begin{array}{l}\text { Clinical phenotypes of } \\
\text { mild-to-moderate OSA + } \\
\text { unsupervised K-means } \\
\text { cluster analysis (n=1184, } \\
\text { males } 59.6 \% \text {, single } \\
\text { centre) } \\
\text { No analysis of comorbidities }\end{array}$ & $\begin{array}{l}\text { Phenotype: } \\
\text { REM-predominant } \\
\text { OSA }(45.3 \%) \\
\text { Cluster } 4\end{array}$ & $\begin{array}{l}\text { Phenotype: non-REM } \\
\quad \text { predominant OSA }(18.9 \%) \\
\text { No cluster identified }\end{array}$ & $\begin{array}{l}\text { Phenotype: } \\
\text { supine-predominant } \\
\text { OSA } 160.4 \%) \\
\text { Clusters } 1 \text { and } 2\end{array}$ & $\begin{array}{l}\text { Phenotype: intermittent OSA } \\
\quad[12.7 \%) \\
\text { No cluster identified }\end{array}$ & $\begin{array}{l}\text { Phenotype: isolated supine } \\
\text { OSA (29.8\%): as in group } \\
\text { 3, but nonsupine AHI <5 } \\
\text { Cluster } 3\end{array}$ & $\begin{array}{l}\text { Phenotype: isolated REM } \\
\text { OSA: as in group 1, but } \\
\text { non-REM AHI <5- } \\
\text { No cluster identified }\end{array}$ & $\begin{array}{l}\text { Phenotype: REM-supine } \\
\text { overlap (20.5\%) } \\
\text { Clusters } 5 \text { and } 6\end{array}$ & \\
\hline$Y_{E}[87]$ & $\begin{array}{l}\text { Latent class analysis in } \\
\text { newly diagnosed } \\
\text { moderate-to-severe OSA } \\
\text { (n=822, males } 81 \% \text {, ISAC) } \\
\text { Comorbidities: hypertension, } \\
\text { diabetes, CVD, obstructive } \\
\text { lung disease }\end{array}$ & $\begin{array}{l}\text { Disturbed sleep: } \\
32.7 \% \text { of the } \\
\text { sample (males } \\
78.4 \% \text {, mean age: } \\
54.1 \text { years); } \\
\text { insomnia and } \\
\text { other nocturnal } \\
\text { symptoms, mean } \\
\text { ESS } 9.5 \% \\
\text { Comorbidities: } \\
\text { hypertension } \\
47.8 \% \text {, diabetes } \\
8.8 \% \text {, CVD } 14.4 \% \text {, } \\
\text { obstructive lung } \\
\text { disease } 21.3 \%\end{array}$ & $\begin{array}{l}\text { Minimally symptomatic: } \\
24.7 \% \text { of the sample } \\
\text { (males } 83.7 \% \text {, mean age: } \\
56.6 \text { years); few mild } \\
\text { symptoms, mean ESS } \\
7.9 \% \\
\text { Comorbidities: hypertension } \\
\text { 49.6\%, diabetes } 10.5 \% \text {, } \\
\text { CVD } 18.3 \% \text {, obstructive } \\
\text { lung disease } 16.2 \%\end{array}$ & $\begin{array}{l}\text { EDS: } 42.6 \% \text { of the } \\
\text { sample Imales } \\
\text { 81.4\%, mean age: } \\
53.6 \text { years); classic } \\
\text { OSA presentation } \\
\text { and sleepiness- } \\
\text { related symptoms, } \\
\text { mean ESS 15.7\% } \\
\text { Comorbidities: } \\
\text { hypertension } 41.6 \% \text {, } \\
\text { diabetes } 7.5 \%, \text { CVD } \\
11.9 \% \text {, obstructive } \\
\text { lung disease } 18.2 \%\end{array}$ & & & & & \\
\hline VAvougios [88] & $\begin{array}{l}\text { Categorical PCA and } \\
\text { two-step clustering in } \\
\text { consecutive OSA patients } \\
\text { (n=1472, males } 83.9 \% \text {, } \\
\text { single centre) } \\
\text { Charlson Comorbidity Index }\end{array}$ & $\begin{array}{l}\text { Phenotype A: healthy, } \\
\text { reporting } \\
\text { sleep-related } \\
\text { symptoms, } \\
\text { moderate EDS, } \\
\text { Cluster } 3,16.6 \% \text { of } \\
\text { the sample Imales } \\
65 \% \text {, mean age } \\
43.9 \text { years, mean } \\
\text { BMI } 28 \mathrm{~kg} \cdot \mathrm{m}^{-2} \text {, } \\
\text { mean ESS } 6.77 \\
\text { Comorbidities: } \\
\text { CHF } 0.8 \%, \text { CAD } \\
2 \% \text {, hypertension } \\
20.5 \%\end{array}$ & $\begin{array}{l}\text { Phenotype B: mild OSA, few } \\
\text { comorbidities } \\
\text { Cluster 1, 19.6\% of the } \\
\text { sample Imales } 81 \% \text {, mean } \\
\text { age } 48.2 \text { years, mean BMI } \\
29.2 \mathrm{~kg} \cdot \mathrm{m}^{-2} \text {, mean ESS } \\
7.11 \\
\text { Comorbidities: CHF } 0.3 \% \text {, } \\
\text { CAD 6.2\%, hypertension } \\
25.6 \%\end{array}$ & $\begin{array}{l}\text { Phenotype } \mathrm{C}_{1} \text { : } \\
\text { moderate OSA, } \\
\text { obesity, no } \\
\text { comorbidities } \\
\text { (males } 85 \% \text {, mean } \\
\text { age } 50.2 \text { years, } \\
\text { mean BMI } \\
30.7 \mathrm{~kg} \cdot \mathrm{m}^{-2} \text {, mean } \\
\text { ESS } 8.5 \text { ) } \\
\text { Comorbidities: CAD } \\
7.5 \% \text {, hypertension } \\
\text { 33.6\%) }\end{array}$ & $\begin{array}{l}\text { Phenotype } \mathrm{C}_{2} \text { : moderate } \\
\text { OSA, obesity, severe } \\
\text { comorbidities and stroke } \\
\text { Cluster 2, } 7.1 \% \text { of the } \\
\text { sample (males } 80 \% \text {, mean } \\
\text { age } 61.2 \text { years, mean BMI } \\
33.5 \mathrm{~kg} \cdot \mathrm{m}^{-2} \text {, mean ESS } \\
\text { 9.1) } \\
\text { Comorbidities: CHF } 23.1 \% \text {, } \\
\text { CAD } 33.7 \% \text {, hypertension } \\
73.1 \%, \text { COPD } 36.5 \% \\
\text { stroke } 31.7 \% \text {, diabetes } \\
44.2 \%\end{array}$ & $\begin{array}{l}\text { Phenotype } \mathrm{D}_{1} \text { : severe } 0 \mathrm{SA}_{\text {, }} \\
\text { obesity, no comorbidities } \\
\text { other than hypertension } \\
\text { in } 33.8 \% \\
\text { Cluster } 4,31.3 \% \text { of the } \\
\text { sample (males } 94 \% \text {, mean } \\
\text { age } 47.4 \text { years, mean BMI } \\
33.1 \mathrm{~kg} \cdot \mathrm{m}^{-2} \text {, mean ESS } \\
\text { 10.3) } \\
\text { Comorbidities: } \\
\text { hypertension } 33.8 \%\end{array}$ & $\begin{array}{l}\text { Phenotype } \mathrm{D}_{2}: \text { severe } 0 \mathrm{SA} \text {, } \\
\text { obesity, severe } \\
\text { comorbidities, highest } \\
\text { ESS and BMI } \\
\text { Cluster } 5,10.0 \% \text { of the } \\
\text { sample (males } 91 \% \text {, mean } \\
\text { age } 58.8 \text { years, mean BMI } \\
35.6 \mathrm{~kg} \cdot \mathrm{m}^{-2} \text {, mean ESS } \\
11.6) \\
\text { Comorbidities: CHF } 40.5 \% \text {, } \\
\text { CAD } 54.7 \%, \text { hypertension } \\
76.4 \% \text {, COPD } 23 \% \text {, } \\
\text { diabetes } 29.1 \%\end{array}$ & & \\
\hline SAARESRANTA [89] & $\begin{array}{l}\text { Four clinical presentations } \\
\text { based on daytime- } \\
\text { nocturnal symptoms } \\
\text { (n=6555, males } 75,4 \%, \\
\text { ESADA cohort) } \\
\text { Comorbidities explored: } \\
\text { cardiovascular metabolic, } \\
\text { respiratory and psychiatric }\end{array}$ & $\begin{array}{l}\text { EDS-no insomnia } \\
\text { phenotype, } 20.7 \% \\
\text { of the sample } \\
\text { (males } 77.2 \% \text {, } \\
\text { mean age } \\
51.5 \text { years, BMl } \\
>30 \mathrm{~kg} \cdot \mathrm{m}^{-2}: \\
56.3 \% \text {, mean ESS } \\
14.9 \text { ) } \\
\text { Comorbidities: } \\
\text { cardiovascular } \\
48.9 \%, \text { psychiatric } \\
8.7 \%\end{array}$ & $\begin{array}{l}\text { EDS-insomnia phenotype, } \\
23.7 \% \text { of the sample } \\
\text { (males } 71.8 \% \text {, mean age } \\
52.2 \text { years, BMI } \\
>30 \mathrm{~kg} \cdot \mathrm{m}^{-2}: 61.4 \% \text {, mean } \\
\text { ESS } 14.8 \text { ) } \\
\text { Comorbidities: } \\
\text { cardiovascular } 53 \% \text {, } \\
\text { psychiatric } 14.5 \%\end{array}$ & $\begin{array}{l}\text { No EDS-no insomnia } \\
\text { phenotype, } 25.8 \% \text { of } \\
\text { the sample Imales } \\
83.0 \% \text {, mean age } \\
52.8 \text { years, BMI } \\
>30 \mathrm{~kg} \cdot \mathrm{m}^{-2}: 51.5 \% \text {, } \\
\text { mean ESS } 6.1] \\
\text { Comorbidities: } \\
\text { cardiovascular } 52 \% \text {, } \\
\text { psychiatric } 5 \%\end{array}$ & $\begin{array}{l}\text { No EDS-insomnia phenotype, } \\
29.8 \% \text { of the sample } \\
\text { (males } 70.4 \% \text {, mean age } \\
54.6 \text { years, BMI } \\
>30 \mathrm{~kg} \cdot \mathrm{m}^{-2}: 52.3 \% \text {, mean } \\
\text { ESS } 6.0 \text { ) } \\
\text { Comorbidities: } \\
\text { cardiovascular } 56.8 \% \text {, } \\
\text { psychiatric } 12.6 \%\end{array}$ & & & & \\
\hline
\end{tabular}




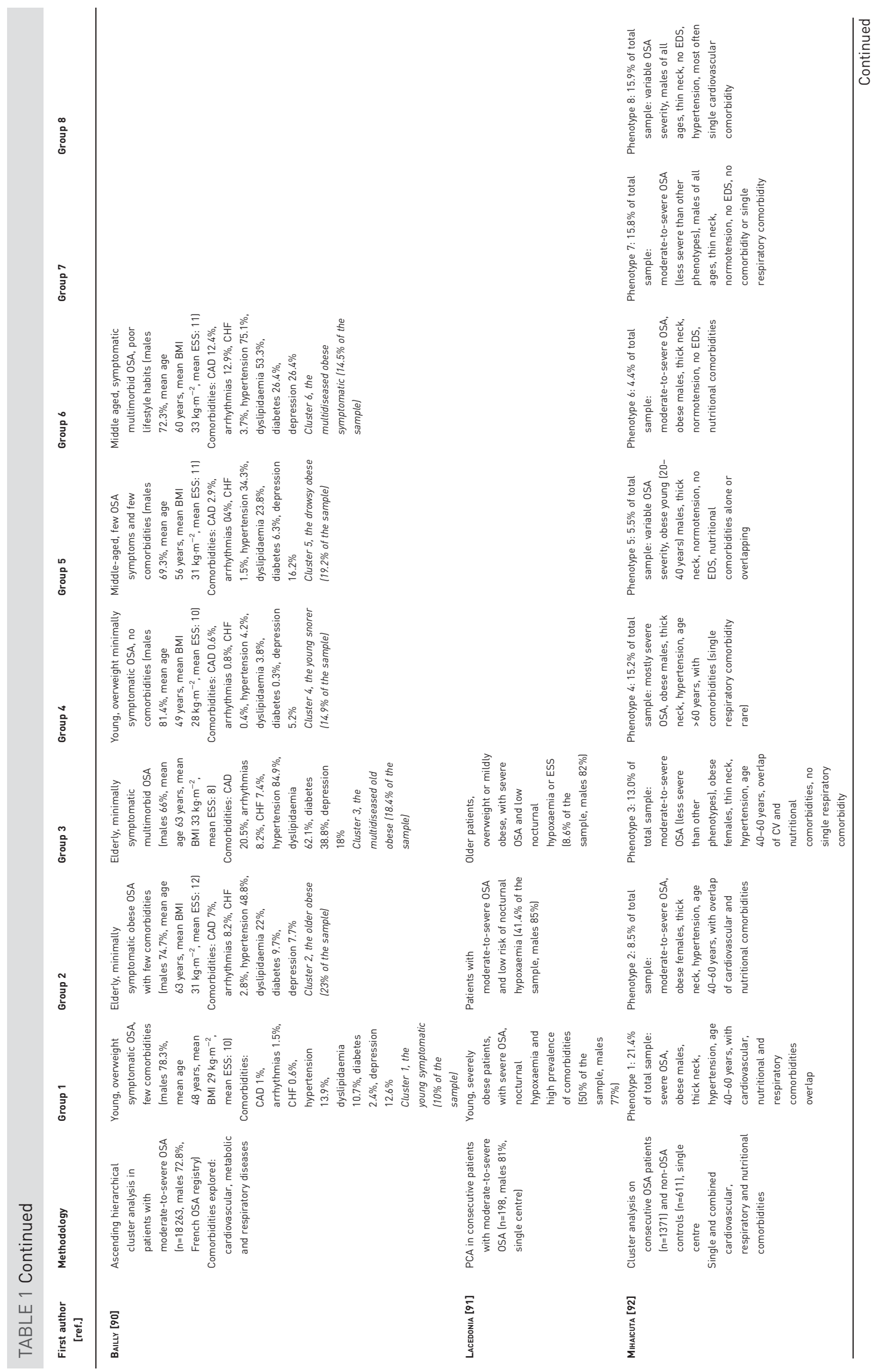




\begin{tabular}{|c|c|c|c|c|c|c|c|c|c|}
\hline $\begin{array}{l}\text { First author } \\
\text { [ref.] }\end{array}$ & Methodology & Group 1 & Group 2 & Group 3 & Group 4 & Group 5 & Group 6 & Group 7 & Group 8 \\
\hline GaGnadoux [93] & $\begin{array}{l}\text { Latent class analysis in } \\
\text { moderate-to-severe OSA } \\
\text { (n=5983, 71.1\% males), } \\
\text { multicentre prospective } \\
\text { sleep cohort; CPAP } \\
\text { compliance (n=3090) } \\
\text { Comorbidities: } \\
\text { cardiovascular, } \\
\text { hypertension, diabetes } \\
\text { CPAP success defined as } \\
\text { use at } 6 \text { months } \\
\geqslant 4 \mathrm{~h} \text {-night-1 }+ \text { ESS } \\
\text { decrease by } \geqslant 4 \text { points in } \\
\text { patients with baseline ESS } \\
\geqslant 11 \text { or increase of } \\
7 \text { points in energy/vitality } \\
\text { score }\end{array}$ & 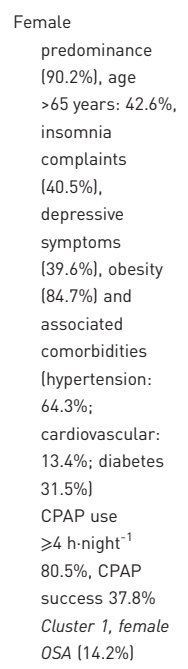 & 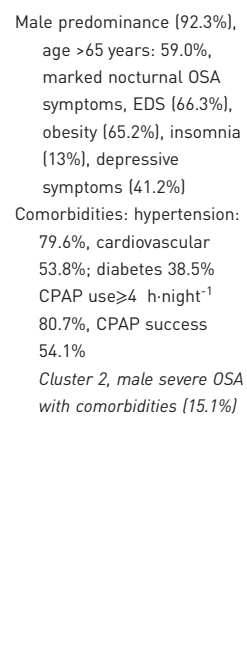 & $\begin{array}{l}\text { Male predominance } \\
\text { (61.7\%), age } \\
\text { >65 years: } 3.6 \% \text {, } \\
\text { marked nocturnal } \\
\text { OSA symptoms, } \\
\text { EDS (197.6\%), } \\
\text { obesity }(53.6 \%), \\
\text { insomnia (2.9\%), } \\
\text { depressive } \\
\text { symptoms (34.5\%) } \\
\text { Comorbidities: } \\
\text { hypertension } 13.0 \% \text {, } \\
\text { cardiovascular: } 3.6, \\
\text { diabetes } 4.2 \% \\
\text { CPAP use } \geqslant 4 \\
\text { h.night } 75.8 \%, \\
\text { CPAP success } \\
\text { 57.6\% } \\
\text { Cluster 3., severe OSA } \\
\text { (18.2\%) }\end{array}$ & $\begin{array}{l}\text { Male predominance }(83.4 \%) \text {, } \\
\text { age }>65 \text { years: } 19.8 \%, \\
\text { nocturnal } 0 \text { A symptoms, } \\
\text { obesity (30.3\%), insomnia } \\
\text { complaints (32.4\%), } \\
\text { depressive symptoms } \\
\text { (7.2\%) low prevalence of } \\
\text { EDS }(29.5 \%) \text { or } \\
\text { comorbidities } \\
\text { (hypertension: } 6.3 \% ; \\
\text { cardiovascular: } 3.5 \% ; \\
\text { diabetes } 0 \%) \\
\text { CPAP use } \geqslant 4 \text { h.night }{ }^{-1} \\
79.5 \%, \text { CPAP success } \\
39 \% \\
\text { Cluster } 4, \text { mildly } \\
\text { symptomatic OSA (32\%) }\end{array}$ & $\begin{array}{l}\text { Male predominance }(87.0 \%) \text {, } \\
\text { age }>65 \text { years: } 66.7 \% \text {, low } \\
\text { frequency of nocturnal } \\
\text { OSA symptoms, obesity } \\
\text { (64.4\%), insomnia } \\
\text { complaints }[21.5 \%) \text {, } \\
\text { depressive symptoms } \\
(2.2 \%) \text { low prevalence of } \\
\text { EDS }(16.4 \%) \text {, high } \\
\text { prevalence of } \\
\text { comorbidities } \\
\text { (hypertension: } 74.8 \% \text {, } \\
\text { cardiovascular } 37.6 \% \text {, } \\
\text { diabetes } 31 \%) \\
\text { CPAP use } \geqslant 4 \text { h.night }{ }^{-1} \\
85.5 \%, \text { CPAP success } \\
25.7 \% \\
\text { Cluster 5, comorbid OSA } \\
\text { (20.5\%) }\end{array}$ & & & \\
\hline ВавBIN [94] & $\begin{array}{l}\text { Time-series analysis followed } \\
\text { by dynamic cluster } \\
\text { analysis to identify } \\
\text { patterns of CPAP use } \\
\text { over } 6 \text { months (nn=161, } \\
\text { OSA features or } \\
\text { comorbidities not } \\
\text { specified), single centre }\end{array}$ & $\begin{array}{l}\text { Great CPAP users } \\
\quad(17.2 \%) \text { : mean } \\
\text { use } 7.3 \mathrm{~h} \cdot n \text { night } \\
\text { no slope over } \\
\text { time }\end{array}$ & $\begin{array}{l}\text { Good CPAP users (32.8\%): } \\
\text { mean use } 5.7 \mathrm{~h} \cdot \mathrm{night}{ }^{-1} \\
\text { no slope over time }\end{array}$ & $\begin{array}{l}\text { Low users }(22.7 \%) \text { : } \\
\text { mean use } \\
2.3 \mathrm{~h} \cdot \text { night }^{-1} \text {, } \\
\text { decreasing slope } \\
\text { over time } \\
\left(-0.013 \mathrm{~h} \cdot \text { night }^{-1}\right)\end{array}$ & $\begin{array}{l}\text { Slow decliners }(27.3 \%) \text { : mean } \\
\text { use } 4.3 \mathrm{~h} \cdot \mathrm{night}^{-1} \text {, } \\
\text { decreasing slope over } \\
\text { time }\left(-0.007 \mathrm{~h} \cdot \text { night }^{-1}\right)\end{array}$ & & & & \\
\hline
\end{tabular}

REM: rapid eye movement; AHI: apnoea/hypopnoea index; ISAC: Icelandic Sleep Apnoea Cohort; CVD: cardiovascular disease; ESS: Epworth Sleepiness Scale; EDS: excessive daytime sleepiness (i.e. ESS $\geqslant 10$ ); PCA: principal component analysis; BMI: body mass index; CHF: chronic heart failure; CAD: coronary artery disease; COPD: chronic obstructive pulmonary disease; ESADA: European Sleep Apnea Database. 


\begin{tabular}{|c|c|c|}
\hline Variable & $\begin{array}{l}\text { First author } \\
\text { [reference] }\end{array}$ & Results \\
\hline \multirow[t]{3}{*}{ Insomnia symptoms } & $Y_{E}[87]$ & Disturbed sleep cluster \\
\hline & SAARESRANTA [89] & EDS+insomnia+ phenotype; EDS-insomnia+ phenotype \\
\hline & GAGNADOUX [93] & Female OSA (cluster 1), comorbid OSA (cluster 6) \\
\hline \multirow[t]{7}{*}{ EDS } & $Y_{E}[87]$ & EDS cluster \\
\hline & VAVOUGIOS [88] & Clusters 4 and 5 \\
\hline & SAARESRANTA [89] & EDS+insomnia+ phenotype; EDS-insomnia+ phenotype \\
\hline & BAILLY [90] & $\begin{array}{l}\text { Young symptomatic OSA (cluster 1); drowsy obese (cluster } \\
\text { 5), multimorbid OSA (cluster 6) }\end{array}$ \\
\hline & MIHAICUTA [92] & Clusters 1-4 \\
\hline & GAGNADOUX [93] & Clusters 2 and 3 \\
\hline & LACEDONIA [91] & Cluster 1 \\
\hline \multirow[t]{7}{*}{ Female OSA } & $Y_{E}[87]$ & $\begin{array}{l}\text { Disturbed sleep cluster (lowest percentage of male } \\
\text { patients) }\end{array}$ \\
\hline & VAVOUGIOS [88] & Not identified \\
\hline & SAARESRANTA [89] & Not identified \\
\hline & BAILLY [90] & Not identified \\
\hline & LACEDONIA [91] & Not identified \\
\hline & MIHAICUTA [92] & Clusters 2 and 3 \\
\hline & GAGNADOUX [93] & Cluster 1 \\
\hline \multirow{7}{*}{$\begin{array}{l}\text { Comorbid OSA, few OSA } \\
\text { symptoms }\end{array}$} & $Y_{E}[87]$ & Minimally symptomatic cluster \\
\hline & VAVOUGIOS [88] & Cluster 2 \\
\hline & SAARESRANTA [89] & No EDS/no insomnia phenotype \\
\hline & BAILLY [90] & Cluster 3 \\
\hline & LACEDONIA [91] & Cluster 3 \\
\hline & MIHAICUTA [92] & Clusters 4 and 5 \\
\hline & GaGnadoux [93] & Cluster 5 \\
\hline \multirow[t]{3}{*}{ Young, severe OSA } & BAILLY $[94]$ & $\begin{array}{l}\text { Young symptomatic OSA (cluster 1) and young snorer } \\
\text { without comorbidities (cluster } 4 \text { ) }\end{array}$ \\
\hline & LACEDONIA [91] & Cluster 1 \\
\hline & MiHAICUTA [92] & Cluster 7 \\
\hline \multirow[t]{4}{*}{ Elderly OSA patients } & BAILLY [90] & $\begin{array}{l}\text { Older obese (cluster 2) and the multidiseased old obese } \\
\text { (cluster 3) }\end{array}$ \\
\hline & LACEDONIA [91] & Cluster 3 \\
\hline & MIHAICUTA [92] & Cluster 4 \\
\hline & GaGnADOUX [93] & Clusters 4 and 5 \\
\hline
\end{tabular}

EDS: excessive daytime sleepiness.

multicentre large cohort [89]. Results were similar to those of $\mathrm{YE}$ et al. [87] and coworkers, with an additional finding of a high prevalence of psychiatric comorbidities, especially in OSA patients reporting symptoms of insomnia.

In addition, the role of comorbidities was considered in the study by VAVOugIos et al. [88]. These authors identified four main clinical phenotypes, corresponding to increasing severity of OSA, and six clusters, with no OSA and mild OSA as single clusters, moderate and severe OSA each subdivided into two clusters according to the presence or absence of significant comorbidities. Two studies, the largest to date, were published in 2016 on OSA patients from two French registries [90, 93]. BAILly et al. [90] identified six clusters in the French OSA registry (>18000 patients), corresponding to patients of different ages, with variable OSA severity and comorbidity burdens. GAGNADOux et al. [93] identified five clusters in the multicentre prospective sleep cohort of the Institut de Recherche en Santé Respiratoire des Pays de la Loire (almost 6000 patients); interestingly, two clusters featured female OSA and OSA in minimally symptomatic elderly patients.

Two additional cluster analyses were published recently, which used different variables compared to other studies. In a small single-centre study, LACEDONIA et al. [91] stratified the patients with moderate-severe OSA according to the level of nocturnal hypoxaemia and identified three clusters. Severe nocturnal hypoxaemia was found in relatively young, severely obese patients who accounted for about half of the total sample, whereas elderly patients with mild nocturnal hypoxaemia and few symptoms accounted for 
$\sim 8 \%$ of the total sample. Finally, Minaicuta et al. [92] published a detailed single-centre study including $>1300$ OSA patients and >600 controls, and identified eight clusters. This complex study assessed not only single comorbidities, but also their overlap in OSA patients, and identified two clusters of female OSA.

What clinical message can we derive from these studies on clinical presentations of OSA? Table 2 summarises the main clinical traits and the corresponding clusters identified in the different studies, suggesting that an overall picture of different phenotypes/clusters is slowly emerging. Pulmonologists dealing with OSA patients are becoming aware that females and elderly patients, or minimally symptomatic patients with cardiovascular or metabolic comorbidities, or OSA patients without sleepiness, do represent different presentations of the disease. It can be foreseen that clinical OSA presentations will eventually be combined with physiological phenotypes of OSA in order to choose the best treatment strategy for each individual patient.

Cluster analysis has also been applied to assess the outcome of CPAP treatment (table 1). In the study by GAGNADOUx et al. [93], CPAP success after 6 months of treatment (expressed as mean nightly use for $\geqslant 4 \mathrm{~h}$, and decrease in ESS score of $\geqslant 4$ points, or improvement of $\geqslant 7$ points in the 36 -item Short Form survey score) was highest in cluster 3 , corresponding to severe highly symptomatic OSA, and lowest in cluster 5 , corresponding to the minimally symptomatic patients with significant comorbidities. At least two studies have reported poor compliance to CPAP treatment in patients with symptoms of insomnia [95, 96]. Cluster analysis has also been used to define patterns of CPAP use, since mean nightly use of CPAP incompletely describes the trajectory of CPAP use over time in single patients. BABBIN et al. [94] identified four clusters of CPAP users, from the great user who used CPAP for most of the night without major variations over time, to the low user and the slow decliner, who used CPAP for insufficient time each night and tended to abandon treatment. These results are important to identify groups of patients in whom an intervention to improve compliance to CPAP treatment may be warranted. Unfortunately, the clinical characteristics of the patients according to the clusters of CPAP use were not included in the study.

\section{Conclusions}

Progress of personalised medicine in OSA and clinical application of results can be expected in the near future, since variability in clinical presentation and physiological trait-driven therapeutic strategies are increasingly recognised. Research on "-omics" (figure 1) continues, and may ultimately provide clinically useful biomarkers for adult [97] and paediatric [29, 98, 99] OSA. Examples are studies in adults and children with OSA using proteomics $[29,100]$, studies on miRNA in patients with OSA and resistant hypertension [101], the application of system biology to genetic studies of OSA [102] and studies on visceral fat transcriptome to assess the molecular basis of the interaction between OSA and obesity [103, 104]. A roadmap for a personalised approach to OSA has been proposed according to P4 medicine, (personalisation, prediction, prevention and patient participation in healthcare) [27, 28]. This huge effort is expected to change the current paradigm of OSA diagnosis and treatment, since AHI-based stratification of patients has revealed many pitfalls, similar to the forced expiratory volume in $1 \mathrm{~s}$-based stratification of COPD patients, and is clearly insufficient to define the complexity of the disease. Moreover, the scientific community is currently experiencing a deep rethinking on the opportunity to prescribe CPAP in patients who are little or minimally symptomatic, since compliance to treatment is poor in this population, as confirmed by recent randomised controlled studies on patients with cardiovascular disease and OSA [105]. New and personalised treatment strategies for OSA are necessary and will foster better patient care, while improving our understanding of this complex disease.

\section{References}

1 Wenzel SE. Asthma phenotypes: the evolution from clinical to molecular approaches. Nat Med 2012; 18: 716-725.

2 Ray A, Oriss TB, Wenzel SE. Emerging molecular phenotypes of asthma. Am J Physiol Lung Cell Mol Physiol 2015; 308: L130-L140.

3 Agustí A, Vestbo J. Current controversies and future perspectives in chronic obstructive pulmonary disease. Am J Respir Crit Care Med 2011; 184: 507-513.

4 Agusti A, Sobradillo P, Celli B. Addressing the complexity of chronic obstructive pulmonary disease: from phenotypes and biomarkers to scale-free networks, systems biology, and P4 medicine. Am J Respir Crit Care Med 2011; 183: 1129-1137.

5 Woodruff PG, Agusti A, Roche N, et al. Current concepts in targeting chronic obstructive pulmonary disease pharmacotherapy: making progress towards personalised management. Lancet 2015; 385: 1789-1798.

6 Melosky B. Current treatment algorithms for patients with metastatic non-small cell, non-squamous lung cancer. Front Oncol 2017; 7: 38.

7 Soldera SV, Leighl NB. Update on the treatment of metastatic squamous non-small cell lung cancer in new era of personalized medicine. Front Oncol 2017; 7: 50.

8 Budhiraja R, Thomas R, Kim M, et al. The role of big data in the management of sleep-disordered breathing. Sleep Med Clin 2016; 11: 241-255. 
Bianchi MT, Russo K, Gabbidon H, et al. Big data in sleep medicine: prospects and pitfalls in phenotyping. Nat Sci Sleep 2017; 9: 11-29. apnoea-hypopnoea with or without treatment with continuous positive airway pressure: an observational study. Lancet 2005; 365: 1046-1053.

11 Bucks RS, Olaithe M, Eastwood P. Neurocognitive function in obstructive sleep apnoea: a meta-review. Respirology 2013; 18: 61-70.

12 Tregear S, Reston J, Schoelles K, et al. Obstructive sleep apnea and risk of motor vehicle crash: systematic review and meta-analysis. J Clin Sleep Med 2009; 5: 573-581.

13 Weiss JW, Tamisier R, Liu Y. Sympathoexcitation and arterial hypertension associated with obstructive sleep apnea and cyclic intermittent hypoxia. J Appl Physiol 2015; 119: 1449-1454.

14 Hoyos CM, Drager LF, Patel SR. OSA and cardiometabolic risk: what's the bottom line? Respirology 2017; 22: 420-429.

15 Gozal D, Farré R, Nieto FJ. Obstructive sleep apnea and cancer: epidemiologic links and theoretical biological constructs. Sleep Med Rev 2016; 27: 43-55.

16 Bonsignore MR, McNicholas WT, Montserrat JM, et al. Adipose tissue in obesity and obstructive sleep apnoea. Eur Respir J 2012; 39: 746-767.

17 Gozal D, Gileles-Hillel A, Cortese R, et al. Visceral white adipose tissue after chronic intermittent and sustained hypoxia in mice. Am J Respir Cell Mol Biol 2017; 56: 477-487.

18 Zinchuk AV, Gentry MJ, Concato J, et al. Phenotypes in obstructive sleep apnea: a definition, examples and evolution of approaches. Sleep Med Rev 2017; 35: 113-123.

19 Bazzano LA, Hu T, Bertisch SM, et al. Childhood obesity patterns and relation to middle-age sleep apnoea risk: the Bogalusa Heart Study. Pediatr Obes 2016; 11: 535-542.

20 Varvarigou V, Dahabreh IJ, Malhotra A, et al. A review of genetic association studies of obstructive sleep apnea: field synopsis and meta-analysis. Sleep 2011; 34: 1461-1468.

21 Liang J, Cade BE, Wang H, et al. Comparison of heritability estimation and linkage analysis for multiple traits using principal component analyses. Genet Epidemiol 2016; 40: 222-232.

22 Chi L, Comyn FL, Keenan BT, et al. Heritability of craniofacial structures in normal subjects and patients with sleep apnea. Sleep 2014; 37: 1689-1698.

23 Agha B, Johal A. Facial phenotype in obstructive sleep apnea-hypopnea syndrome: a systematic review and meta-analysis. J Sleep Res 2017; 26: 122-131.

24 Lozo T, Komnenov D, Badr MS, et al. Sex differences in sleep disordered breathing in adults. Respir Physiol Neurobiol 2017; 245: 66-75.

25 Edwards BA, Wellman A, Sands SA, et al. Obstructive sleep apnea in older adults is a distinctly different physiological phenotype. Sleep 2014; 37: 1227-1236.

26 Sériès F. Sleep apnoea syndrome: how will physiologic knowledge position personalised medicine? Eur Respir Rev 2011; 20: 127-129.

27 Pack AI. Application of Personalized, Predictive, Preventative, and Participatory (P4) medicine to obstructive sleep apnea. A roadmap for improving care? Ann Am Thorac Soc 2016; 13: 1456-1467.

28 Lim DC, Sutherland K, Cistulli PA, et al. P4 medicine approach to obstructive sleep apnoea. Respirology 2017; 22: 849-860.

29 Khalyfa A, Gileles-Hillel A, Gozal D. The challenges of precision medicine in obstructive sleep apnea. Sleep Med Clin 2016; 11: 213-226.

30 Peppard $\mathrm{P}$, Young T, Barnet $\mathrm{JH}$, et al. Increased prevalence of sleep-disordered breathing in adults. Am J Epidemiol 2013; 177: 1006-1014.

31 Young T, Palta M, Dempsey J, et al. Burden of sleep apnea: rationale, design, and major findings of the Wisconsin Sleep Cohort study. WMJ 2009; 108: 246-249.

32 Edwards B, Eckert D, Jordan A. Obstructive sleep apnoea pathogenesis from mild to severe: is it all the same? Respirology 2017; 22: 33-42.

33 Joosten S, Edwards B, Wellman A, et al. The effect of body position on physiological factors that contribute to obstructive sleep apnea. Sleep 2015; 38: 1469-1478.

34 Wellman A, Eckert DJ, Jordan AS, et al. A method for measuring and modeling the physiological traits causing obstructive sleep apnea. J Appl Physiol 2011; 110: 1627-1637.

35 Edwards BA, Sands SA, Owens RL, et al. Effects of hyperoxia and hypoxia on the physiological traits responsible for obstructive sleep apnoea. J Physiol 2014; 592: 4523-4535.

36 Lim D, Pack A. Obstructive sleep apnea: update and future. Annu Rev Med 2017; 68: 99-112.

37 White DP. Pathogenesis of obstructive and central sleep apnea. Am J Respir Crit Care Med 2005; 172: 1363-1370.

38 Owens RL, Edwards BA, Eckert DJ, et al. An integrative model of physiological traits can be used to predict obstructive sleep apnea and response to non positive airway pressure therapy. Sleep 2015; 38: 961-970.

39 Bosi M, de Vito A, Gobbi R, et al. The importance of obstructive sleep apnoea and hypopnea pathophysiology for customized therapy. Eur Arch Otorhinolaryngol 2017; 274: 1251-1261.

40 Pierce R, White D, Malhotra A, et al. Upper airway collapsibility, dilator muscle activation and resistance in sleep apnoea. Eur Respir J 2007; 30: 345-353.

41 Huon LK, Liu SY, Shih TT, et al. Dynamic upper airway collapse observed from sleep MRI: BMI-matched severe and mild OSA patients. Eur Arch Otorhinolaryngol 2016; 273: 4021-4026.

42 Eckert D. Phenotypic approaches to obstructive sleep apnoea - new pathways for targeted therapy. Sleep Med Rev 2016.

43 Kim AM, Keenan BT, Jackson N, et al. Tongue fat and its relationship to obstructive sleep apnea. Sleep 2014; 37: $1639-1648$.

44 Genta P, Schorr F, Eckert D, et al. Upper airway collapsibility is associated with obesity and hyoid position. Sleep 2014; 37: 1673-1678.

45 Brown EC, Cheng S, McKenzie DK, et al. Tongue stiffness is lower in patients with obstructive sleep apnea during wakefulness compared with matched control subjects. Sleep 2015; 38: 537-544. 
Sands SA, Eckert DJ, Jordan AS, et al. Enhanced upper-airway muscle responsiveness is a distinct feature of overweight/obese individuals without sleep apnea. Am J Respir Crit Care Med 2014; 190: 930-937.

Kim HY, Bok KH, Dhong HJ, et al. The correlation between pharyngeal narrowing and the severity of sleep-disordered breathing. Otolaryngol Head Neck Surg 2008; 138: 289-293.

Bachar G, Feinmesser R, Shpitzer T, et al. Laryngeal and hypopharyngeal obstruction in sleep disordered breathing patients, evaluated by sleep endoscopy. Eur Arch Otorhinolaryngol 2008; 265: 1397-1402.

Owens R, Eckert D, Yeh S, et al. Upper airway function in the pathogenesis of obstructive apnea: a review of the current literature. Curr Opin Pulm Med 2008; 14: 519-524.

Sher AE, Schechtman K, Piccirillo J. The efficacy of surgical modifications of the upper airway in adults with obstructive sleep apnea syndrome. Sleep 1996; 19: 156-177.

Carberry JC, Jordan AS, White DP, et al. Upper airway collapsibility (Pcrit) and pharyngeal dilator muscle activity are sleep stage dependent. Sleep 2016; 39: 511-521.

Farré R, Rigau J, Montserrat JM, et al. Static and dynamic upper airway obstruction in sleep apnea: role of the breathing gas properties. Am J Respir Crit Care Med 2003; 168: 659-663.

Owens RL, Malhotra A, Eckert DJ, et al. The influence of end-expiratory lung volume on measurements of pharyngeal collapsibility. J Appl Physiol 2010; 108: 445-451.

Penzel T, Möller M, Becker HF, et al. Effect of sleep position and sleep stage on the collapsibility of the upper airways in patients with sleep apnea. Sleep 2001; 24: 90-95.

Insalaco G, Romano S, Marrone O, et al. A new method of negative expiratory pressure test analysis detecting upper airway flow limitation to reveal obstructive sleep apnea. Chest 2005; 128: 2159-2165.

Hirata R P, Schorr F, Kayamori F, et al. Upper airway collapsibility assessed by negative expiratory pressure while awake is associated with upper airway anatomy. J Clin Sleep Med 2016; 12: 1339-1346.

Edwards B, White DP. Control of the pharyngeal musculature during wakefulness and sleep: Implications in normal controls and sleep apnea. Head Neck 2011; 33: Suppl. 1, S37-S45.

Fogel RB, Trinder J, White DP, et al. The effect of sleep onset on upper airway muscle activity in patients with sleep apnoea versus controls. J Physiol 2005; 564: 549-562.

Jordan AS, White DP, Lo YL, et al. Airway dilator muscle activity and lung volume during stable breathing in obstructive sleep apnea. Sleep 2009; 32: 361-368.

Jordan AS, Wellman A, Heinzer RC, et al. Mechanisms used to restore ventilation after partial upper airway collapse during sleep in humans. Thorax 2007; 62: 861-867.

Dotan Y, Pillar G, Schwartz AR, et al. Asynchrony of lingual muscle recruitment during sleep in obstructive sleep apnea. J Appl Physiol 2015; 118: 1516-1524.

Bilston LE, Gandevia SC.: Biomechanical properties of the human upper airway and their effect on its behavio during breathing and in obstructive sleep apnea. J Appl Physiol 2014; 116: 314-324.

Wellman A, Jordan AS, Malhotra A, et al. Ventilatory control and airway anatomy in obstructive sleep apnea. Am J Respir Crit Care Med 2004; 170: 1225-1232.

Younes M. CrossTalk proposal: elevated loop gain is a consequence of obstructive sleep apnoea. J Physiol 2014 592: 2899-2901.

Dert D, White DP, Jordan AS, et al. Defining phenotypic causes of obstructive sleep apnea. Identification of novel therapeutic targets. Am J Respir Crit Care Med 2013; 188: 996-1004.

Deacon NL, Catcheside PG. The role of high loop gain induced by intermittent hypoxia in the pathophysiology of obstructive sleep apnoea. Sleep Med Rev 2015; 22: 3-14.

Loewen A, Ostrowski M, Laprairie J, et al. Determinants of ventilatory instability in obstructive sleep apnea: inherent or acquired? Sleep 2009; 32: 1355-1365.

Salloum A, Rowley JA, Mateika JH, et al. Increased propensity for central apnea in patients with obstructive sleep apnea: effect of nasal continuous positive airway pressure. Am J Respir Crit Care Med 2010; 181: 189-193.

Edwards BA, Sands SA, Eckert DJ, et al. Acetazolamide improves loop gain but not the other physiological traits causing obstructive sleep apnoea. J Physiol 2012; 590: 1199-1211.

Jordan AS, O'Donoghue FJ, Cori JM, et al. Physiology of arousal in obstructive sleep apnea and potential impacts for sedative treatment. Am J Respir Crit Care Med 2017; 196: 814-821.

Eckert DJ, Younes MK. Arousal from sleep: implications for obstructive sleep apnea pathogenesis and treatment. J Appl Physiol 2014; 116: 302-313.

Respir Dis 1990; 142: 295-300.

Younes M. Role of arousals in the pathogenesis of obstructive sleep apnea. Am J Respir Crit Care Med 2004; 169: 623-633.

Amatoury J, Azarbarzin A, Younes M, et al. Arousal intensity is a distinct pathophysiological trait in obstructive sleep apnea. Sleep 2016; 39: 2091-2100. Sleep 2015; 38: 899-906. stimulation in obstructive sleep apnoea. Thorax 2016; 71: 923-931.

Taranto-Montemuro L, Sands SA, Edwards BA, et al. Desipramine inprov reduces OSA severity in patients with minimal muscle compensation. Eur Respir J 2016; 48: 1340-1350.

Edwards B, Sands S, Eckert D, et al. Acetazolamide improves loop gain but not the other physiological traits causing obstructive sleep apnoea. J Physiol 2012; 590: 1199-1211.

Landry SA, Joosten SA, Sands SA, et al. Response to a combination of oxygen and a hypnotic as treatment for obstructive sleep apnoea is predicted by a patient's therapeutic CPAP requirement. Respirology 2017; 22: 1219-1224.

Eckert D, Owens R, Kehlmann G, et al. Eszopiclone increases the respiratory arousal threshold and lowers the apnoea/hypopnoea index in obstructive sleep apnoea patients with a low arousal threshold. Clin Sci 2011; 120: 505-514.

1 Li Y, Owens RL, Sands S, et al. The effect of donepezil on arousal threshold and apnea-hypopnea index. A randomized, double-blind, cross-over study. Ann Am Thorac Soc 2016; 13: 2012-2018. 
Carter SG, Berger MS, Carberry JC, et al. Zopiclone increases the arousal threshold without impairing genioglossus activity in obstructive sleep apnea. Sleep 2016; 39: 757-766.

Smith PR, Sheikh KL, Costan-Toth C, et al. Eszopiclone and zolpidem do not affect the prevalence of the low arousal threshold phenotype. J Clin Sleep Med 2017; 13: 115-119.

Shin W, Jen R, Li Y, et al. Tailored treatment strategies for obstructive sleep apnea. Respir Investig 2016; 54: 2-7.

Edwards BA, Landry S, Joosten SA, et al. Personalized medicine for obstructive sleep apnea therapies: are we there yet? Sleep Med Clin 2016; 11: 299-311.

Joosten SA, Hamza K, Sands S, et al. Phenotypes of patients with mild to moderate obstructive sleep apnoea as confirmed by cluster analysis. Respirology 2012; 17: 99-107.

Ye L, Pien GW, Ratcliffe SJ, et al. The different clinical faces of obstructive sleep apnoea: a cluster analysis. Eur Respir J 2014; 44: 1600-1607.

Vavougios GD, George DG, Pastaka C, et al. Phenotypes of comorbidity in OSAS patients: combining categorical principal component analysis with cluster analysis. J Sleep Res 2016; 25: 31-38.

Saaresranta T, Hedner J, Bonsignore MR, et al. Clinical phenotypes and comorbidity in European sleep apnoea patients. PLoS One 2016; 11: e0163439.

Bailly S, Destors M, Grillet Y, et al. Obstructive sleep apnea: a cluster analysis at time of diagnosis. PLoS One 2016; 11: e0157318.

Lacedonia D, Carpagnano GE, Sabato R, et al. Characterization of obstructive sleep apnea-hypopnea syndrome (OSA) population by means of cluster analysis. J Sleep Res 2016; 25: 724-730.

Mihaicuta S, Udrescu M, Topirceanu A, et al. Network science meets respiratory medicine for OSAS phenotyping and severity prediction. PeerJ 2017; 5: e3289.

Gagnadoux F, Le Vaillant M, Paris A, et al. Relationship between OSA clinical phenotypes and CPAP treatment outcomes. Chest 2016; 149: 288-290.

Babbin SF, Velicer WF, Aloia MS, et al Identifying longitudinal patterns for individuals and subgroups: an example with adherence to treatment for obstructive sleep apnea. Multivariate Behav Res 2015; 50: 91-108.

Pieh C, Bach M, Popp R, et al. Insomnia symptoms influence CPAP compliance. Sleep Breath 2013; 17: 99-104.

Eysteinsdottir B, Gislason T, Pack AI, et al. Insomnia complaints in lean patients with obstructive sleep apnea negatively affect positive airway pressure treatment adherence. J Sleep Res 2017; 26: 159-165.

Arnardottir ES, Mackiewicz M, Gislason T, et al. Molecular signatures of obstructive sleep apnea in adults: a review and perspective. Sleep 2009; 32: 447-470.

an HL, Kheirandish-Gozal L, Gozal D. The promise of translational and personalised approaches for paediatric obstructive sleep apnoea: an 'omics' perspective. Thorax 2014; 69: 474-480.

2017; 151: 500-506.

Feliciano A, Torres VM, Vaz F, et al. Overview of proteomics studies in obstructive sleep apnea. Sleep Med 2015; 16: $437-445$.

Sanchez-de-la-Torre M, Khalyfa A, Sánchez-de-la-Torre A, et al. Precision medicine in patients with resistan hypertension and obstructive sleep apnea: blood pressure response to continuous positive airway pressure treatment. J Am Coll Cardiol 2015; 66: 1023-1032.

Liu Y, Patel S, Nibbe R, et al. Systems biology analyses of gene expression and genome wide association study data in obstructive sleep apnea. Pac Symp Biocomput 2011: 14-25.

modulating visceral fat transcriptome. Sleep 2013; 36: 23-30.

Gharib SA, Khalyfa A, Abdelkarim A, et al. Intermittent hypoxia activates temporally coordinated transcriptional programs in visceral adipose tissue. J Mol Med 2012; 90: 435-445.

McEvoy RD, Antic NA, Heeley E, et al. CPAP for prevention of cardiovascular events in obstructive sleep apnea. N Engl J Med 2016; 375: 919-931. 